\title{
RISK COMMUNICATION AND THE COMMUNITY RESPONSE TO A BIOTERRORIST ATTACK: THE ROLE OF AN INTERNET-BASED EARLY WARNING SYSTEM A.K.A. "THE INFORMAL SECTOR"
}

\author{
Marjorie Pollack \\ ProMED-mail, International Society for Infectious Diseases, \\ Boston, MA, USA
}

\section{Introduction}

Most agencies involved in disease surveillance and response to outbreaks, both natural and unnatural, agree that no single system provides the necessary information that will lead to timely reports of unusual health events. Current discussions point toward the need for a "network of networks" to provide wide coverage into the community for early alerts of these unusual health events. ProMED-mail is an example of an entity operating in the "informal sector" and demonstrates how it can assist in the early communication of new or ongoing disease risks not only to the health-care community, but also the interested community at large, through a moderated Internet-based listserv with a worldwide coverage [1, 2].

The formal health sector has traditionally relied upon reports of disease received through established surveillance systems in which the information travels up the familiar health pyramid (see Figure 1).

According to the above model, the events leading up to an official report on disease occurrence requires multiple steps until the first notification to the formal sector occurs. A local health facility sends a report (usually on a weekly basis) to the next level of attention (county or district level). This level then sends a weekly report to the state or provincial level, which in turn sends a report to the national level. Finally, the national level will send a report to the international level, usually the regional office of the World Health Organization (WHO), which forwards it to WHO headquarters in Geneva.

One of the challenges to getting these reports moving quickly is difficulty in communication between the health facility and the corresponding next higher level for reporting. Another key challenge arises when the person(s) who is ill does not go to an official or governmental health sector facility for the first line of care. In many areas there are private 


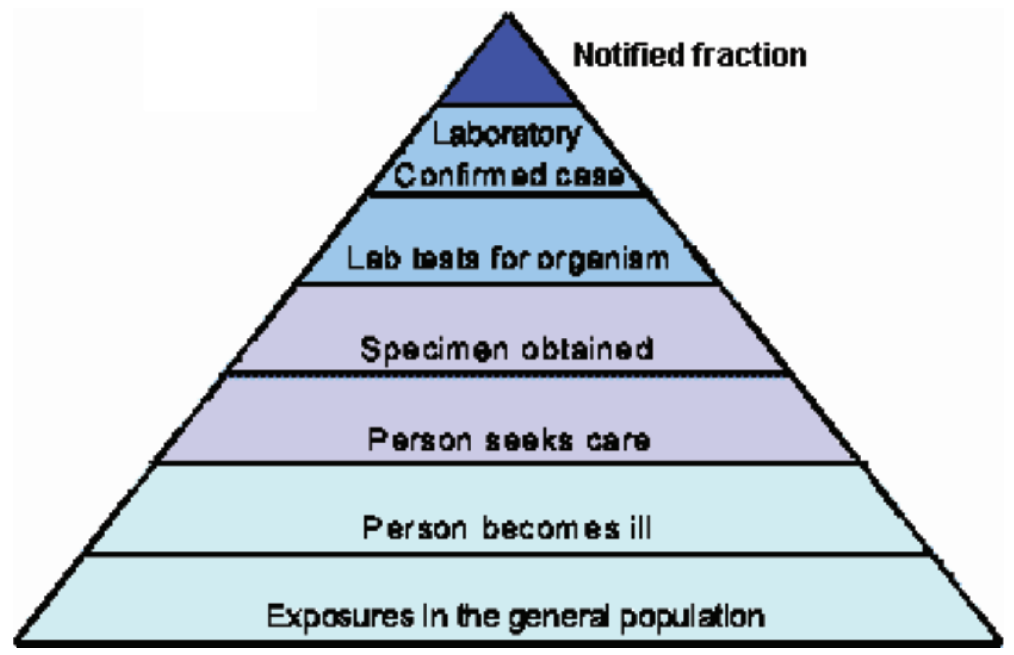

Figure 1. Communicable disease surveillance pyramid [3].

health-care providers, some formally trained, others informally trained, who provide care but are not part of the official reporting network. Hence, the official sector often does not learn about these cases until long after when they first present for treatment.

Recognizing the limitations confronting the formal health sector, especially in the domain of communication of possible disease problems, the Program to Monitor Emerging Diseases, better known as ProMED was formed in 1994. ProMED-mail is a global electronic reporting system, open to all sources, for outbreaks of emerging infectious diseases and diseases resulting from toxin exposure. It is a moderated listserv that covers plant, animal, and human diseases. Subscriptions are free, and there is a freely accessible website at: http://www.promedmail.org. ProMEDmail is a program activity of the International Society of Infectious Diseases and is a not-for-profit, non-governmental organization (NGO). This independent status permits ProMED to function without political constraints. (This translates into the ability to post reports without requiring the permission of a government to do so.)

At the time of this workshop (June 2005), there were more than 33,000 subscribers to ProMED-mail from more than 150 countries. ProMED-mail postings are reproduced on numerous other listservs and it is estimated that postings will reach approximately 100,000 computers each day. All reports posted on ProMED-mail are screened by expert moderators. Fields of expertise of the moderators include viral, bacterial, fungal, and parasitic diseases; epidemiology and surveillance; entomology; and veterinary and plant diseases. 
Posted reports come from a variety of sources. Official, "formal sector" reports from regional, national, and international public health authorities are often posted to provide official confirmation of an outbreak or unusual health event.

However, the use of the "informal sector" is crucial for the acquisition of information or reports on unusual health events as they are occurring. The two main sources are lay press reports and anecdotal reports submitted by subscribers. The subscriber base in over 150 countries constitutes an international network of individuals with access to information on unusual health events (see Figure 2 for a map of ProMED-mail subscribers).

ProMED-mail subscribers include members of the international official (governmental) sector: the WHO and its regional offices, the Food and Agricultural Organization of the United Nations (FAO), and the World Animal Health Organization (OIE). There are Ministry of Health and Ministry of Agriculture personnel at the national level. It also includes members of the scientific community (at the project or field level, at the organizational level, including NGOs, and at the academic level) and nonscientific community, including members of the lay press. Often, although the official health sector may not as yet have seen cases of new diseases of concern, the lay press publishes reports on these outbreaks. ProMED-mail staff and subscribers search the Internet for such reports and post them on the listserv.

With subscribers in more than 150 countries, reports of unusual health events in one country serve as an alert for "astute clinicians" in other countries. The public health arena recognizes the important role of the astute clinician in identifying new geographic spread of diseases.

ProMED-mail focuses on the coverage of newly described or undiagnosed diseases, outbreaks, epidemics of known infectious diseases, and the emergence of known diseases in newly defined geographic areas or among newly defined populations. This applies to human diseases as well as animal and plant diseases. Animal diseases covered include zoonotic diseases with known or suspected human disease potential, as well as purely animal diseases for their ultimate impact on economies and that pertaining to food security. Similarly, plant diseases are covered for their known impact on human health as well as for economic and food security issues (Table 1). Estimates are that more than $70 \%$ of newly emerging diseases are zoonotic in origin, resulting in "species jump" from animal to humans $[1,4]$. Recent examples of this include the severe acute respiratory syndrome (SARS), avian influenza, Nipah virus encephalitis, spongiform encephalopathies, and monkeypox. 


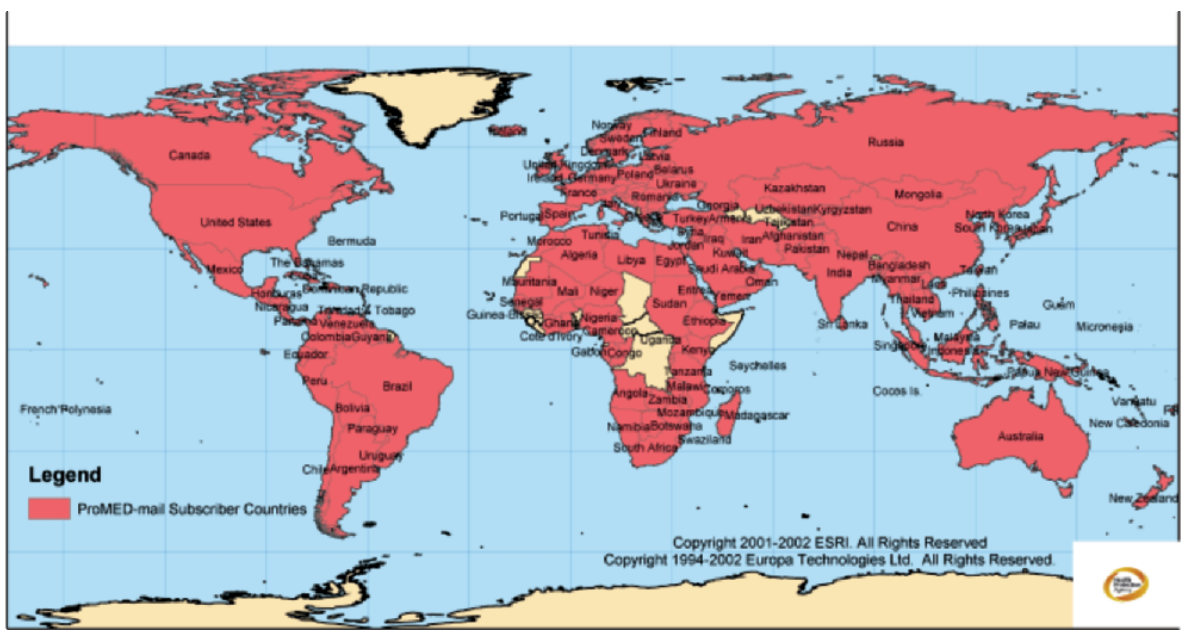

Figure 2. Map of countries with ProMED-mail subscribers.

TABLE 1. Number of ProMED-mail reports, 1994-2005, by disease, for the 18 most the ommonly reported diseases*

\begin{tabular}{ll}
\hline Disease & No. of reports \\
\hline West Nile virus & 831 \\
Dengue & 818 \\
Avian influenza & 746 \\
Foot and mouth disease & 744 \\
Bovine spongiform encephalopathy & 695 \\
Cholera & 684 \\
Rabies & 668 \\
Anthrax & 599 \\
Unknown illness & 563 \\
Ebola & 474 \\
Escherichia coli O157 & 454 \\
New variant Creutzfeldt-Jakob-disease & 405 \\
Salmonella & 376 \\
Hantavirus & 336 \\
Yellow fever & 326 \\
Influenza & 323 \\
Malaria & 322 \\
SARS & 249 \\
\hline
\end{tabular}

* As of 5 June 2005.

\section{Examples of use of Informal Sector}

Examples of increased response by the health community to heightened disease surveillance needs facilitated through the informal sector can be seen in the reporting of four recent outbreaks. 


\subsection{SEVERE ACUTE RESPIRATORY SYNDROME (SARS)}

On 10 February 2003, the following posting appeared on ProMED-mail:

PNEUMONIA - CHINA (GUANGDONG): REQUEST
FOR INFORMATION
$* * * * * * * * * * * * * * * * * * * * * * * * * * * * * * * * * * * * * * * * * * * * * * *$
Date: 10 Feb 2003
From: Stephen O. Cunnion, MD, PhD, MPH
This morning I received this e-mail and then searched
your archives and found nothing that pertained to it. Does
anyone know anything about this problem?
"Have you heard of an epidemic in Guangzhou? An
acquaintance of mine from a teacher's chat room lives
there and reports that the hospitals there have been closed
and people are dying"'[5].

This report was the first public notification of an outbreak in southern China of a disease that was later called SARS. By the end of the outbreak in July 2003, 8,096 probable cases of SARS had been reported with 774 deaths [6].

For the first month, after the outbreak, there were numerous reports and rumors from China about an epidemic of a severe, "atypical" pneumonia. On 11 March 2003, there was a ProMED-mail posting reporting an illness with similar symptoms in a businessman visiting Hanoi, followed by similar illnesses among hospital staff that had cared for him [7]. On 14 March 2003, ProMED-mail had received the following email from an infectious disease physician in Ontario, Canada (unpublished e-mail):

We have an unidentified severe respiratory illness cluster in a family, one of whom was in Hong Kong 14 days ago. Can you update me on what the illness cluster in Hanoi is please?

The family cluster described in the above e-mail were the index cases for the outbreak of SARS in Ontario, Canada that by its end had affected 251 individuals with 43 deaths. This e-mail is an excellent example of an astute clinician seeing cases of a new disease that appeared similar to reports of cases occurring on the other side of the world.

The physicians in Ontario published their experiences with SARS and credited Internet-based reporting for its impact on disease identification and containment: 
The identification of SARS in Canada only a few weeks after an outbreak on another continent exemplifies the ease with which infectious agents can be transmitted in this era of international travel. It also demonstrates the importance and value of information and alert systems such as the Department of Communicable Disease Surveillance Response of the World Health Organization [WHO] and the Disease Outbreak News Web site (http:// www.who.int/csr/don) and the ProMED-mail (Program for Monitoring Emerging Diseases) reporting network sponsored by the International Society for Infectious Disease (http:// www.promedmail.org) [1; 8, page 2003].

The sequence of events leading up to the worldwide alert about SARS clearly demonstrates the value of the informal sector in early disease alerts:

10 Feb 2003 - Reports of atypical pneumonia in Guangdong China - Source: ProMED subscriber, plus newswire report (Chinese) - (informal sector).

11 Feb 2003 - Confirmation of atypical pneumonia in Guangdong China - Source: Official WHO report (formal sector), newswires (informal sector).

11 Mar 2003 - Reports of undiagnosed respiratory illness in hospital in Hanoi VietNam - Source: Newswire (informal sector). 14 Mar 2003 - Reports of atypical pneumonia in East Asia Hong Kong, Vietnam, Singapore, China (Guangdong Province), Taiwan, and Ontario Canada - Source: Official (WHO, HK $\mathrm{DOH}, \mathrm{CDC}$ Taiwan) (formal sector) hospital staff, newswires (informal sector).

15 Mar 2003 - Reports of SARS worldwide - Source: WHO advisory/alert (formal sector).

\subsection{AVIAN INFLUENZA}

The public health community clearly acknowledges that we are long overdue for a human influenza pandemic. It has long been theorized that new human influenza strains evolve as species jumps by avian influenza viruses, which through genetic reassortment obtain human-to-human transmissibility genes [9]. The appearance of a new strain of avian influenza associated with human illness has been a serious concern on the part of the public health community, as a possible precursor to the next human influenza pandemic. The following report was posted on ProMED-mail on 20 August 1997: 


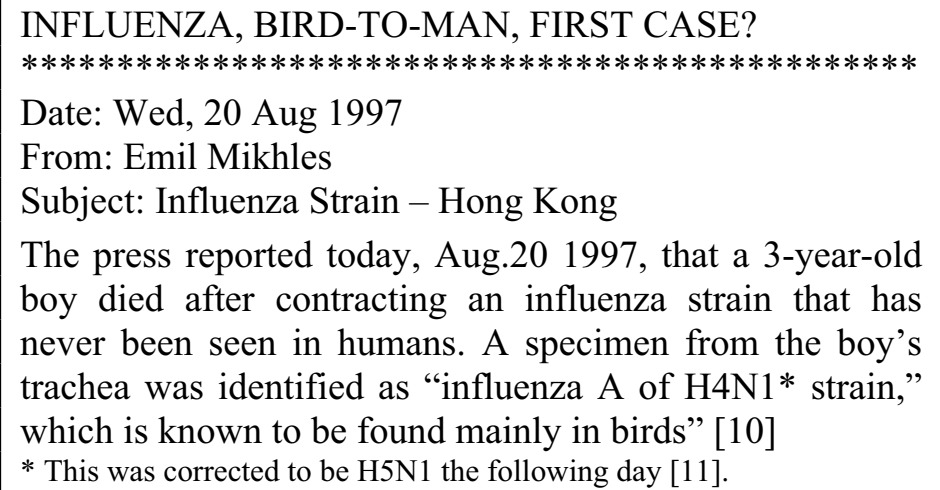

This report focused worldwide attention on the possibility that H5N1 would be the next pandemic influenza strain. At that time, H5N1 had been identified in poultry in live markets in Hong Kong and it was speculated that there were ongoing unreported outbreaks of H5N1 on the Chinese mainland [12]. During the early stages of the SARS outbreak, there were two cases of confirmed human illness with H5N1 among family members who had traveled from Fujian Province in China to Hong Kong, where their illness was diagnosed; a third suspected case was a family member who died while still in Fujian Province [13].

Following these human cases, the public health community followed the H5N1 activity in both avian and human populations. The avian H5N1 had first been identified in a goose in China in 1996 [14]. The next official report of an outbreak of $\mathrm{H} 5 \mathrm{~N} 1$ in avians was in Hong Kong, following the identification of a human case of H5N1 [15].

Following these events, there were no official reports of H5N1 activity until 2004. Early reports of suspected avian influenza outbreaks were appearing in the informal sector, as seen below:

\section{AVIAN INFLUENZA - INDONESIA: REQUEST FOR INFORMATION}

$* * * * * * * * * * * * * * * * * * * * * * * * * * * * * * * * * * * * * * * *$

Date: 18 November 2003

From: ProMED-mail <promed@promedmail.org>

ProMED-mail has received a report from a reliable source of rumors of the occurrence of an outbreak of avian influenza in domestic fowl in Indonesia (West Java and Sumatra). The accounts of the rumored outbreak emanate from 2 independent sources.

Further information from any informed person or organization in the area would be appreciated [Mod.CP] [16] 
The reliable source providing this report was a veterinarian working in the affected area, who was concerned about political and professional repercussions for publicly reporting this outbreak. Job security concerns are often deterrents to international reporting. Through the use of the informal network, it was possible to alert the official sector of the suspicion of an avian influenza outbreak among poultry, without jeopardizing the reporting individual. The official report of an avian influenza outbreak ongoing in Indonesia was made to the OIE on 4 February 2004 [17]. In this instance there was a time lag of 3 months between the informal sector notification of a suspected outbreak and the formal sector notification.

A similar time lag was seen with the early reports of suspected avian influenza in Thailand. On 5 January 2004, the following was posted on ProMED-mail:

\begin{tabular}{l}
\hline AVIAN INFLUENZA - THAILAND: RFI \\
$* * * * * * * * * * * * * * * * * * * *$ \\
Date: Sun, 5 Jan 2004 \\
From: ProMED-mail <promed@promedmail.org> \\
Source: Malaysia Star, 5 Jan 2004 [edited] \\
$<$ http://www.thestar.com.my/news/story.asp?file=2004/1/ \\
5/nation/7036583\&sec=nation> \\
Penang farmers fear smuggled Thai chicks may spread \\
bird flu \\
----------------------------------------------- \\
The Penang Poultry Farmers Association has voiced \\
concerns about the possibility of live chicken smuggled \\
from Thailand being infected with the bird flu... report \\
yesterday that the Terengganu Livestock Breeders \\
Association had urged the state Veterinary Services \\
Department to control the entry of chicken from Thailand \\
following the detection of a virus that causes avian \\
influenza among birds in that country [18].
\end{tabular}

The Thailand Department of Livestock refuted the above report on 9 January 2004, stating that the outbreak was due to fowl cholera, with the following caveat: "However, there might have been some confusion with an outbreak [in] mid-November 2003, of mixed infection of fowl cholera (Pasteurella multocida type A) and acute pasteurellosis (Pasteurella haemolytica) in one layer farm [of] about 68000 birds at Nong Bua district in Nakorn Sawan province" [19]. 
In response to the early reports on suspected avian influenza in Thailand, the Thai Ministry of Health increased human influenza surveillance in provinces where there had been reports of major poultry dieoffs. On 23 January 2004 there were simultaneous reports confirming avian influenza cases in the avian population, and in three humans [20,21].

Again the sequence of events involved informal sector reports leading to formal sector reports at a later date (approximately 18 days). This demonstrates the importance of the communication of risk and the impact on heightening surveillance.

Similar time lags were also seen with reports of avian influenza in Vietnam.

\subsection{CHIKUNGUNYA - INDIAN OCEAN}

In May 2005, there was a posting on ProMED-mail describing an outbreak of Chikungunya in Mauritius and Reunion Island:

\section{CHIKUNGUNYA - MAURITIUS AND REUNION ISLAND \\ $* * * * * * * * * * * * * * * * * * * * * * * * * * * * * * * * * * * * *$}

Date: Wed, May 18, 2005

From: Mohammad Issack

In Mauritius, since early April 2005, several people have been attending the hospital and health centres of the capital city, Port-Louis, with fever and arthralgia of hands and feet... a rash was also noted.

Chikungunya virus was suspected based on the clinical presentation, the self-limiting course, and the recent report on ProMED-mail of a Chikungunya virus disease epidemic in the Comoros Islands [22].

The reporting physician was an astute clinician who had heard of Chikungunya virus activity in a neighboring island; he decided to send specimens for testing to determine whether a new outbreak in his area might be related. He also mentioned that the first cases in Mauritius occurred near a hostel where many students from the Comoros Islands were lodging [22].

\subsection{CLOSTRIDIUM NOVYI - INJECTING DRUG USERS UNITED KINGDOM}

Injecting drug users frequently present to hospital emergency rooms with overwhelming sepsis, a condition associated with high mortality rates. Because of this, hospital personnel do not generally report these deaths to 
the official health sector as unusual events. In May 2000, ProMED-mail received the following report from an academic veterinarian at the Norwegian Army Medical School:

ANTHRAX, HUMAN - NORWAY: RFI
$* * * * * * * * * * * * * * * * * * * * * * * * * * *$
Date: 6 May 2000
From: Per Lausund
The press (Norwegian Broadcasting Corp.) has reported
that a drug addict (IV heroin) died some days ago from
anthrax. It is reported that the heroin might have been the
source of the bacteria, but at the same time they warn drug
abusers to watch out for sores with black crusts and scabs.
This sounds like cutaneous anthrax. ... On the other hand,
no more deaths or infections have been reported, and if
this was in the drug abusers' heroin it should affect more
than one person.
Anyone heard of similar cases recently? [23]

Based on this report, there was an international alert regarding the possibility of anthrax contaminated heroin, which could constitute intentional introduction of a biologic agent. During this heightened alert, reports began to surface of an increase in deaths among injecting drug users in the UK. On 11 May 2000 there was a newswire report of eight unexplained deaths among injecting drug users in Scotland [24].

By 15 June 2000 there had been reports of 42 cases in Scotland and 20 cases in England and Wales. A diagnosis of disease due to infection with Clostridium novyi was made [25]. Full descriptions of the outbreaks were detailed in the literature, with mention that the initial alert was related to the case of anthrax in the injecting drug user in Norway [26, 27]. A total of 26 cases in England and 82 cases in Scotland and Ireland were identified as related to this outbreak. Retrospective active case finding did identify cases prior to April 2000, further supporting the observation that the heightened alert for adverse health events among injecting drug users, triggered by the anthrax case in Norway, led to the identification of this outbreak.

\section{Lessons Learned}

The key lessons learned from the outbreak investigations detailed above are:

1. We live in a global village where microbial organisms do not need visas for international travel. 
2. No single institution has the capacity to address all needs and cover all bases with respect to disease surveillance.

3. Early alerts are important in preventing rumors and speculation, and in alerting the "astute clinicians" elsewhere to look for possible new problems in their areas.

In the event of an intentional biologic event, a communication of the risk (a disease process or outbreak) will lead to earlier suspicion of the same problem in other geographic areas. In the case of intentional release of a biologic agent, the scope of geographic involvement is not initially known; alerting the community quickly, especially the health-care community is a critical step in enhancing surveillance.

There is consensus that no one organization alone can cover all disease surveillance needs; a network of networks is necessary.

Informal sector reports can lead to formal sector investigations, resulting in earlier identification of emerging infectious diseases. This is especially true when dealing with new diseases (such as Nipah virus and SARS) or in the identification of known diseases in new geographic areas (such as Rift Valley fever on the Arabian peninsula, and West Nile virus infections in the Americas).

\section{Conclusions}

The case studies of outbreak reports presented above serve to underscore the important role the informal sector plays in providing early warnings of disease risks. ProMED-mail is a good example of drawing upon the resources of the informal sector, through a listserv that broadcasts alerts of potential health risks based on reports from individual subscribers and those found in the lay press. This electronic means of communication of potential health risks has been successful as an early warning system for emerging diseases to both the formal health sector as well as the community at large. It further demonstrates that multiple-disease-reporting systems are complementary and enhance the early detection of unusual health events.

The role of the astute clinician cannot be understated. In the event of the intentional release of a biologic agent, early communication of the risk would assist the astute clinician in early recognition of a problem in his or her community.

\section{Acknowledgments}

Editorial assistance and guidance from Paul Guttry and Isaac Druker is very much appreciated. The ProMED-mail Editor, Associate Editors, and 
Moderators must be recognized for their contributions leading to the actual postings on the ProMED-mail service: Lawrence Madoff, Stuart Handysides, Donald Kaye, Jack Woodall, Peter Cowen, J. Allan Dodds, Tam Garland, Martin Hughes-Jones, Larry Lutwick, Eskild Petersen, Craig Pringle, Michael Service, Arnon Shimshony, and Tom Yuill.

\section{References}

1. Madoff LC. ProMED-mail: an early warning system for emerging diseases. CID 2004:39 (15 July) 227-232.

2. Woodall JP. Global surveillance of emerging diseases: the ProMED-mail perspective. Cad. Saúde Pública 2001; 17(Suppl.).

3. Australian Government Department of Health and Aging Australia's notifiable diseases status, 2000: Annual report of the National Notifiable Diseases Surveillance System, Communicable Diseases Intelligence, June 2000; 26(2). Available at: http://www.health.gov.au/internet/wcms/Publishing.nsf/Content/cda-pubs-cdi-2002-cdi2602-cdi2602b6.htm. Accessed 2 January 2007.

4. Cleaveland S, Laurenson MK, Taylor LH. Diseases of humans and their domestic mammals: pathogen characteristics, host range and the risk of emergence. Philos Trans R Soc Lond B Biol Sci 2001; 356:991-999.

5. ProMED-mail. Pneumonia-China (Guangdong): RFI. ProMED-mail archive 20030210.0357. 10 February 2003. Available at: http://www.promedmail.org. Accessed 5 June 2005.

6. World Health Organization, Summary of probable SARS cases with onset of illness from 1 November 2002-31 July 2003 (Based on data as of 31 December 2003). Available at: http://www.who.int/csr/sars/country/ table2004_04_21/en/index.html. Accessed 3 January 2007.

7. ProMED-mail. Undiagnosed illness-Vietnam (Hanoi): RFI. ProMEDmail archive 20030311.0595. 11 March 2003. Available at: http://www. promedmail.org. Accessed 5 June 2005.

8. Poutanen SM, Low DE, Henry B, et al. Identification of severe acute respiratory syndrome in Canada. N Engl J Med 2003; 348:1995-2005.

9. Webster RG, Bean WJ, Gorman OT, Chambers TM, Kawaoka Y. Evolution and ecology of influenza A viruses. Microbiol Mol Biol Rev 1992 March; 56(1): 152-179.

10. ProMED-mail. Influenza, bird-to-man, first case? ProMED-mail archive 19970820.1747. 20 August 1997. Available at: http://www.promedmail.org. Accessed 7 January 2007.

11. ProMED-mail. Influenza, bird-to-man, first case? (02). ProMED-mail archive 19970821.1750. 21 August 1997. Available at: http://www.promedmail.org. Accessed 7 January 2007.

12. ProMED-mail. Influenza, bird-to-man, - China (Hong Kong) (12). ProMEDmail archive 19971209.2452. 9 December 1997. Available at: http:// www.promedmail.org. Accessed 7 January 2007. 
13. ProMED-mail. Influenza, H5N1 human case - China (Hong Kong). ProMEDmail archive 20030219.0428. 19 February 2003. Available at: http:// www.promedmail.org. Accessed 7 January 2007.

14. Sims LD et al. Origin and evolution of highly pathogenic H5N1 avian influenza in Asia. Vet Rec 2005; 157:159.

15. ProMED-mail. Influenza, bird-to-man, first case? (04). Archive 19970825.1766. 25 August 1007. Available at: http://www.promedmail.org. Accessed 7 January 2007.

16. ProMED-mail. Avian influenza - Indonesia: RFI. Archive 20031119.2872. 19 November 2003. Available at: http://www.promedmail.org. Accessed 5 June 2005.

17. ProMED-mail. Avian influenza - Indonesia: OIE Archive 20040204.0413. 4 February 2004. Available at: http://www.promedmail.org. Accessed 5 June 2005. Based on a published report by OIE at a URL no longer accessible.(http://www.oie.int/Messages/040203IDN.htm)

18. ProMED-mail. Avian influenza - Thailand: RFI. Archive 20040105.0051. 5 January 2004. Available at: http://www.promedmail.org. Accessed 5 June 2005.

19. ProMED-mail. Avian influenza - Thailand (02): not confirmed. Archive 20040109.0097. 9 January 2004. Available at: http://www.promedmail.org. Accessed 5 June 2005.

20. ProMED-mail. Avian influenza, Thailand - OIE. Archive 20040124.0276. 24 January 2004. Available at: http://www.promedmail.org. Accessed 5 June 2005.

21. ProMED-mail. Avian influenza, human - Thailand (02): confirmed. Archive 20040123.0262. 23 January 2004. Available at: http://www.promedmail.org. Accessed 5 June 2005.

22. ProMED-mail. Chikungunya - Mauritius and Reunion Island. Archive 20050519.1372. 19 May 2005. Available at: http://www.promedmail.org. Accessed 5 June 2005.

23. ProMED-mail. Anthrax, human - Norway: RFI. Archive 20000506.0119. 6 May 2000. Available at: http://www.promedmail.org. Accessed 5 June 2005.

24. ProMED-mail. Unexplained deaths, human - UK (Scotland). Archive 20000511.0717. 11 May 2000. Available at: http://www.promedmail.org. Accessed 5 June 2005.

25. ProMED-mail. Unexplained deaths, drug addicts - UK: diagnosis. 20000615.0977. 15 June 2000. Available at: http://www.promedmail.org. Accessed 5 June 2005.

26. Jones JA., et al. An outbreak of serious illness and death among injecting drug users in England during 2000. J Med Microbiol 2002; 51: 978-984.

27. Fischer MA. An outbreak of histiotoxic clostridial infections among injection drug users in Scotland and Ireland. Presented at the Intersci Conf Antimicrob Agents Chemother Intersci Conf Antimicrob Agents Chemother 2001 Dec 16-19; 41: abstract no. 2009. Meeting abstract available at: http:/gateway.nlm.nih.gov/MeetingAbstracts/102270101.html. Accessed 7 January 2007. 